\title{
Evolution of the Corrosion-inhibiting Efficiency of Novel Hydrazine Derivatives against Corrosion of Stainless Steel 201 in Acidic Medium
}

\author{
A. S. Fouda ${ }^{1, *}$, S. A. Abd El-Maksoud ${ }^{2}$, A. El-Hossiany ${ }^{3}$, A. Ibrahim ${ }^{1}$ \\ ${ }^{1}$ Department of Chemistry, Faculty of Science, El-Mansoura University, El-Mansoura-35516, Egypt, \\ ${ }^{2}$ Department of Chemistry, Faculty of Science, Port Said University, Port Said, Egypt. \\ ${ }^{3}$ Delta Fertilizers Company in Talkha, Egypt \\ *E-mail: asfouda@hotmail.com
}

doi: $10.20964 / 2019.07 .65$

Received: 4 March 2019 / Accepted: 5 May 2019 / Published: 10 June 2019

\begin{abstract}
The corrosion inhibition effectiveness of some hydrazine derivatives (HD) as corrosion inhibitors for stainless steel (SS 201) in 1.0 M HCl had confirmed using chemical and electrochemical methods. The studies were achieve at various temperatures $\left(25-45^{\circ} \mathrm{C}\right)$. The thermodynamic parameters were determined. HD have been found to be more effective corrosion inhibitors at lower temperatures. Adsorption isotherm was determined and was found to follow Langmuir's adsorption isotherm. Inhibition efficiencies at different HD concentrations were determined using chemical and electrochemical techniques. Polarization data revealed that these HD act as mixed-kind inhibitors. Morphology of the surface was examined utilizing Fourier transform infrared (FTIR) and atomic force microscopy (AFM). The obtained inhibition efficiency from different techniques were in a high agreement, confirming the validity of the used all techniques for stainless steel corrosion in hydrochloric acid medium.
\end{abstract}

Keywords: Corrosion inhibition, Adsorption, SS 201, HCl, AFM, FTIR

\section{$\underline{\text { FULL TEXT }}$}

(C) 2019 The Authors. Published by ESG (www.electrochemsci.org). This article is an open access article distributed under the terms and conditions of the Creative Commons Attribution license (http://creativecommons.org/licenses/by/4.0/). 